P0021

\title{
CHROMATIC DEPENDENCE OF THE CONTRAST SENSITIVITY FUNCTION OF THE PHANTOM ARRAY EFFECT
}

Chan-Su Lee et al.

DOI 10.25039/x46.2019.PO021

from

CIE x046:2019

Proceedings

of the

29th CIE SESSION

Washington D.C., USA, June 14 - 22, 2019

(DOI 10.25039/x46.2019)

The paper has been presented at the 29th CIE Session, Washington D.C., USA, June 14-22, 2019. It has not been peer-reviewed by CIE.

(C) CIE 2019

All rights reserved. Unless otherwise specified, no part of this publication may be reproduced or utilized in any form or by any means, electronic or mechanical, including photocopying and microfilm, without permission in writing from CIE Central Bureau at the address below. Any mention of organizations or products does not imply endorsement by the CIE.

This paper is made available open access for individual use. However, in all other cases all rights are reserved unless explicit permission is sought from and given by the CIE.

CIE Central Bureau

Babenbergerstrasse 9

A-1010 Vienna

Austria

Tel.: +43 17143187

e-mail: ciecb@cie.co.at

www.cie.co.at 


\title{
CHROMATIC DEPENDENCE OF THE CONTRAST SENSITIVITY FUNCTION OF THE PHANTOM ARRAY EFFECT
}

\author{
Lee, C-.S ${ }^{1}$, Hwang, J.S. ${ }^{2}$, Lee, D.H. ${ }^{2}$ \\ 1 Yeungnam University, Gyeongsan, REP. OF KOREA \\ ${ }^{2}$ Korea Research Institute of Standards and Science, Daejon, REP. OF KOREA \\ chansu@ynu.ac.kr, \{jhwang, dh.lee\}@kriss.re.kr
}

DOI 10.25039/x46.2019.PO021

\begin{abstract}
Phantom array effect is one of the temporal light artefacts (TML) that are caused by time modulated light sources. The threshold frequency of the visibility of the phantom array effect can be affected by many components. In this paper, we examined the critical flicker fusion frequency (CFF) and its chromatic dependence of the light sources. The preliminary experimental result shows that contrast sensitivity function to perceive phantom array effect changes in different chromaticity. We need further investigation to find out the relationship between chromaticity and CFF of the phantom array effect.
\end{abstract}

Keywords: Phantom array effect, Temporal light artefact (TLM), Critical Flicker Fusion Frequency (CFF), Chromaticity

\section{Introduction}

Artefacts that caused by time-modulated light source is called temporal light artefacts (TLAs) in $\mathrm{CIE}(\mathrm{CIE}, 2016)$. Several factors that affect visual detection of the phantom array effect have been studied(Vogels, 2012). Our previous study implies chromatic dependence of the threshold frequency of the visibility of the phantom array effect at high modulation frequency(Lee et al., 2016). In this study, the contrast sensitivity functions of the phantom array effect in different chromatic light sources and luminance levels are investigated.

\section{Methods}

New apparatus for the experiment was implemented with Xe light source, 12 bandpass filter wheels, a chopper system, an ND filter, a diffuser, and high dynamic range light booth. 12 bandpass filter from $430 \mathrm{~nm}$ to $670 \mathrm{~nm}$ with $10 \mathrm{~nm}$ band width are used to select the experiment light wavelength from the Xe light source. The selected chromatic light source passed a chopper system which is used to control modulation frequency of the observed light source. Two sets of chopper wheels are used to control modulation frequency from $60 \mathrm{~Hz}$ to $1500 \mathrm{~Hz}$. In the experiment, $60 \mathrm{~Hz}, 80 \mathrm{~Hz}, 100 \mathrm{~Hz}, 150 \mathrm{~Hz}, 300 \mathrm{~Hz}, 600 \mathrm{~Hz}, 900 \mathrm{~Hz}, 1200 \mathrm{~Hz}, 1500 \mathrm{~Hz}, 1800$ $\mathrm{Hz}$ modulation frequencies was evaluated for monochromatic light sources with center wavelengths of $460 \mathrm{~nm}, 530 \mathrm{~nm}, 590 \mathrm{~nm}$, and $650 \mathrm{~nm}$. Originally, there were two bandpass sets with 12 bandpass filters in each set. Total 24 band passed monochromatic light sources can be generated after passing the band pass filters. However, four band pass filters were used in actual experiment to fit luminance level in the experiment. Figure 1 shows the system configuration for the experiment.

Continuously grating ND filters was used to adjust the different wavelength light source to the same luminance level. $400 \mathrm{~cd} / \mathrm{m}^{2}, 100 \mathrm{~cd} / \mathrm{m}^{2}, 25 \mathrm{~cd} / \mathrm{m}^{2}$ luminance level was used in the experiment. By finding the relationship between rotating angle and transmittance rate, we could control the extinction rate and adjust the source luminance of the given bandpass filter to the target luminance. Figure 2 shows an example of a transmittance rate for a light source after passing a given bandpass filter. 


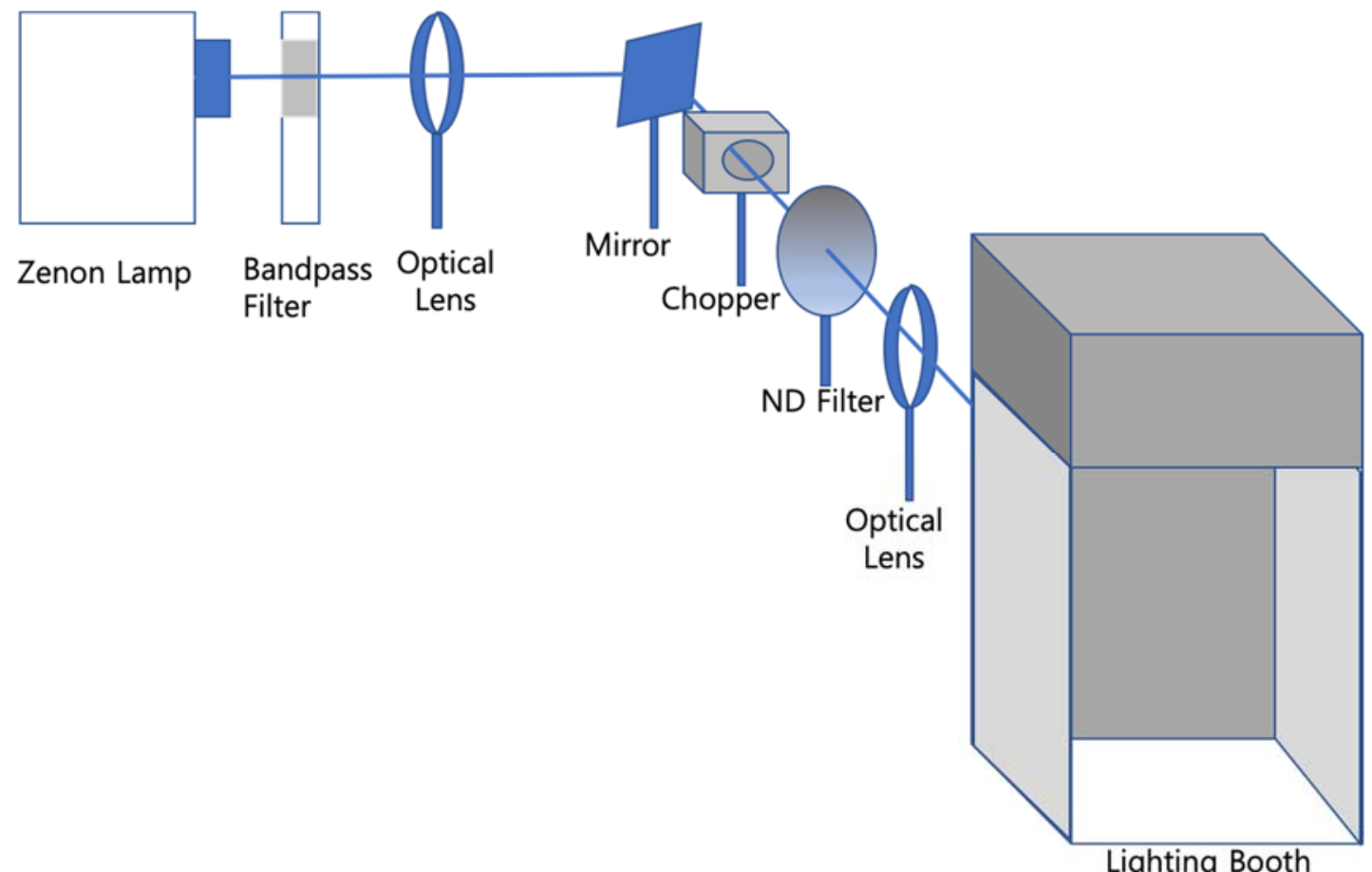

Figure 1 - System setup for the contrast

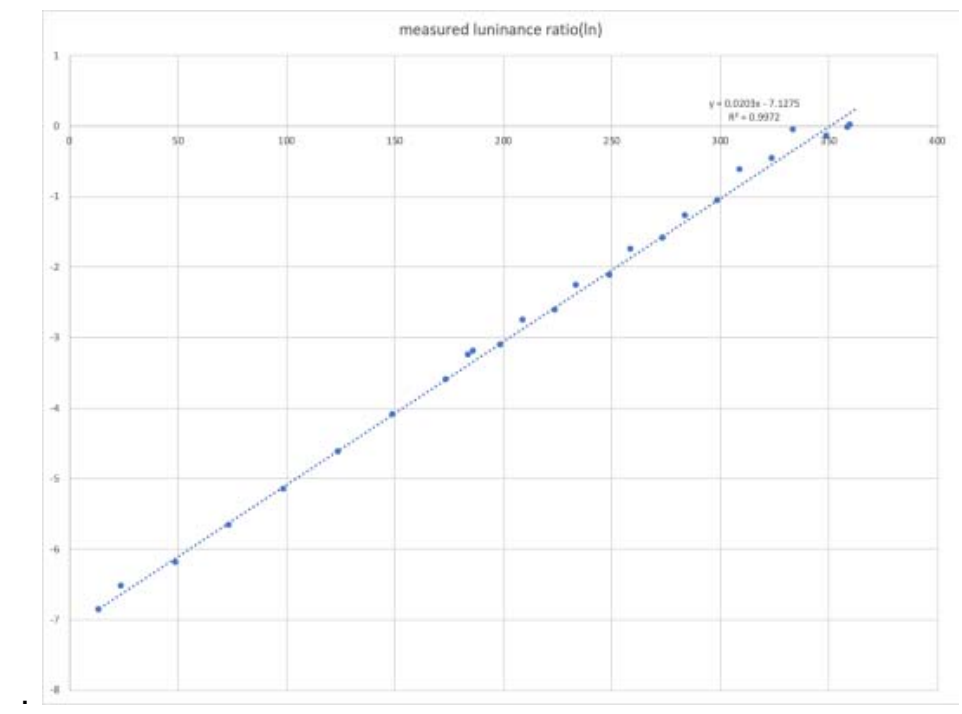

Figure 2 - Relationship between rotation angle and transmittance rate

A lighting booth, implemented to evaluate high dynamic range camera system, was used to precisely adjust background luminance during finding the threshold contrast level of the visibility of the phantom array effect. In our experiment, target contrast was modified by adjusting background luminance using the high dynamic range lighting booth for a fixed foreground luminance in each band light source. When we adjusted the background luminance, the adaptation luminance was also changed in our experiment set-up.

\section{Results}

Preliminary experiment results show that the contrast sensitivity of the phantom array effect depends on the chromaticity of the light source as well as its luminance level not only at high modulation frequency but also at moderate modulation frequency. Table 1 shows contrast sensitivity according to spectral distribution and modulation frequency for $100 \mathrm{~cd} / \mathrm{m}^{2}$ source luminance based on required critical flicker fusion frequency (CFF). 
Table 1 - Contrast sensitivity according to light source spectrum and modulation frequency

\begin{tabular}{|c|c|c|c|c|}
\hline $\begin{array}{l}\text { Modulation } \\
\text { FrequencylWavelength }\end{array}$ & $460 \mathrm{~nm}$ & $530 \mathrm{~nm}$ & $590 \mathrm{~nm}$ & $650 \mathrm{~nm}$ \\
\hline $300 \mathrm{~Hz}$ & 0.0940141 & 0.11268623 & 0.07514845 & 0.0322862 \\
\hline $600 \mathrm{~Hz}$ & 0.0478828 & 0.0840361 & 0.05020792 & 0.01831762 \\
\hline $900 \mathrm{~Hz}$ & 0.03401658 & 0.05488703 & 0.03303908 & 0.01439934 \\
\hline $1200 \mathrm{~Hz}$ & 0.02888614 & 0.05296852 & 0.02828927 & 0.0013697 \\
\hline $1500 \mathrm{~Hz}$ & 0.01094451 & 0.02963106 & 0.00769506 & - \\
\hline $1800 \mathrm{~Hz}$ & 0.01182808 & 0.00142179 & 0.00066003 & 7.48E-05 \\
\hline
\end{tabular}

The peak contrast sensitivity modulation frequency of the phantom array effect, which requires saccadic eye movement during the evaluation of the contrast sensitivity function, is much higher than the peak of the conventional temporal contrast sensitivity function without eye movement.

\section{Discussions}

The preliminary experimental result shows that the contrast sensitivity of the phantom array effect depends on the chromaticity of the light source and is different from the conventional contrast sensitivity. We may need a new contrast sensitivity function to model phantom array effect. We plan to further experiment with additional participants to find out statistical characteristics of the contrast sensitivity function of the phantom array effect compared with conventional contrast sensitivity function.

\section{References}

CIE 2016. TN 006:2016. Visual Aspects of Time-Modulated Lighting Systems-Definitions and Measurement Models Vienna: CIE, 2016.

Vogels IMLC, Hernando I. 2012. Effect of eye movements on perception of temporally modulated light. Proceedings of Experiencing Light, International Conference on the Effects of Light on Wellbeing, Eindhoven, Netherlands: pp. 81-84.

Lee, C.-S., Park, Kim, S.Y., Lee, J.I., Pak, H.S. 2016. Effect of colour and luminance intensity on the phantom array, Proceedings of CIE 2016 Conference, 232-240.

\section{Acknowledgement}

This work was supported by the Human Resources Program in the Transportation Specialized Lighting Core Technology Development (No. N0001364) granted financial resource from the Ministry of Trade, Industry \& Energy, Republic of Korea. 